\title{
Perceptions and Practices: A Survey of Professional Engineers and Architects
}

\author{
Don Cunningham ${ }^{1,2}$ and Jill Stewart ${ }^{3}$ \\ ${ }^{1}$ English Department, Radford University Radford, VA 24141, USA \\ ${ }^{2}$ Language and Culture Institute, Virginia Tech, Blacksburg, VA 24061, USA \\ ${ }^{3}$ Department of Math and Statistics, Radford University, Radford, VA 24141, USA
}

Correspondence should be addressed to Don Cunningham, dacunning@radford.edu

Received 7 December 2011; Accepted 10 January 2012

Academic Editors: T. A. Betts and L. Roecker

Copyright (C) 2012 D. Cunningham and J. Stewart. This is an open access article distributed under the Creative Commons Attribution License, which permits unrestricted use, distribution, and reproduction in any medium, provided the original work is properly cited.

This descriptive cross-sectional research study examines perceptions of time spent by architects and professional engineers on reading, writing, and evaluating various information products, as well as their perspectives of specific quality characteristics and the relative significance in meeting work goals. Professional engineers and architects were surveyed at seminars held at eight locations in seven states. Descriptive statistics were then used to investigate perceptions and relationships. Findings indicate architects and professional engineers spend the most amount of time reading correspondence and the least amount of time reading management reports. Respondents considered correspondence to be the most important reading activity. Participants also spend the most amount of time writing correspondence, closely followed by nearly equal time spent writing and editing technical reports and proposals. Finally, participants rated organization, comprehensiveness, and accuracy as the most important aspects while indicating mechanical issues such as grammar and spelling as the least important aspects of technical documents.

\section{Introduction}

An essential element in the workplace, written communication, allows professionals to read and study information, share information with others, and keep information for future reference. The vitality of the United States economy depends on written communications. Information provides companies with a competitive edge, speeding critical decision making, and allowing job specialization. Clear and accurate communication skills are therefore essential for conducting effective and successful businesses. Conservative estimates indicate US workers spend at least 20 percent of their time writing in a technical or business occupation while professionals in engineering and technology careers spend as much as 40 percent of their time writing [1]. Other studies suggest that writing is the most prevalent activity for professional engineers, requiring as much as 70 percent of their typical workday $[2,3]$.

One of the world's largest and oldest professional association dedicated to the advancement of the field of technical communication, the Society for Technical Communication (STC), recently approved a performance-based certification plan for professional technical communicators. An important aspect of this program is the identification of actual communication tasks performed by practitioners to determine key skills. The STC is currently attempting to validate survey results and rank these core competencies by importance and frequency [4].

Analysis of job postings can provide limited insights into the technical communication skills valued by employers when seeking candidates. The consensus indicates that technical or domain-specific knowledge combined with basic technical writing skills is more highly valued than competency with specific technology tools [5].

Considering the amount of time and effort devoted to on-the-job writing tasks, developing business and professional writing skills should be an important part of the university education of future professional engineers. Collegelevel technical writing courses are supposed to prepare engineering students for professional writing requirements. 
A time-consuming process for both teachers and students, though, the teaching and practice of business and professional writing skills are often limited [6].

Surveys indicate there is considerable variation in the amount of participation in good writing practices and various genres [6]. For most college-level writing assignments, the majority of undergraduate students reported they do not discuss ideas with their instructors beforehand or receive feedback on completed work. Furthermore, almost 80 percent do not take advantage of whatever campus-based or online writing or tutoring services are available [7].

Needs analysis for business and professional writing skills ideally considers both the immediate academic needs of students and their future career needs. Several efforts have been made to examine the role of writing in the classroom and in the workplace. A considerable body of literature addresses immediate academic coursework and research writing task needs $[8,9]$. This research has assisted educators with curriculum design and related instructional material for teaching technical communication.

Surveys of engineering graduates show that writing skills are essential to professional career advancement. The ability to communicate effectively offers additional added value potential which is readily discernable by organization management. Further, the quantity and concentration of technical communication instruction as part of undergraduate education correlated with promotions and overall career success [2].

When it comes to linking theory to practice, though, only limited research has been done to study the actual time spent by frontline professionals on reading, writing, and evaluating various information products or their perspectives on the importance of writing related to meeting specific work goals. Furthermore, identifying elements of written communication which offer the greatest potential to enhance workplace value also requires an effective measurement of product quality. Quantifying effective quality characteristics for information products, though, has proved difficult due to a lack of consensus about those definable elements representing quality [10-15].

University engineering and writing instructors apparently tend to agree on what constitutes good technical communication. In "What is "good" technical communication? A comparison of the standards of writing and engineering instructors," Summer Smith found the criteria for reading and evaluating student writing in the respective disciplines were basically comparable [16]. On the other hand, in "Perceptions of memo quality: A case study of engineering practitioners, professors, and students," Nicole Amare and Charlotte Brammar reported significant gaps in perceptions of workplace writing quality between industry practitioners and postsecondary educators. The responses to textbook business memo examples indicated content and organizational aspects were more important to working engineers while stylistic issues were the most significant to professors [17].

To assess real-world writing perspectives of practitioners, the principal investigator conducted a comprehensive survey of participants at continuing education seminars for architects and professional engineers. The primary objective of this descriptive cross-sectional research study was to collect data on the perceptions of actual working professionals regarding the time spent reading, writing, and evaluating various information products, as well as their perspectives of the importance related to meeting work goals. To identify effective written technical communication characteristics as perceived by working professionals, data was also collected regarding the importance of several quality characteristics and relative significance for effective written technical communications. Under the supervision of their professor, two undergraduate researchers then analyzed the data and used descriptive statistics to investigate perceptions and relationships. The purpose is that these findings about workplace writing tasks may be useful for needs assessment of curricula emphasis and instructional materials so that university students are equipped with skills that allow them not only to pass their classes and graduate, but also to perform with excellence in their future careers.

\section{Research Questions}

The study involved quantitative research and analysis of perceptions of time spent by architects and professional engineers on reading, writing, and evaluating various information products, as well as their perspectives of the importance of these activities in meeting work goals. Information on perceptions of the importance of several quality characteristics and relative significance for effective technical communications was collected to address the following research questions.

(1) How often do architects and professional engineers spend reading and writing information products (correspondence, meeting minutes, technical reports, management reports, proposals, or manuals) and evaluating technical documents?

(2) What are architects and professional engineers' perceptions of the relative importance of these activities in supporting or meeting their professional objectives?

(3) What specific quality characteristics (completeness, stylistic accuracy, technical accuracy, appropriateness, conciseness, correct grammar, and spelling) are considered by architects and professional engineers in evaluating technical documents?

(4) What are architects and professional engineers' perceptions of the relative value of these quality characteristics for effective technical communication?

\section{Methodology}

A survey questionnaire was prepared, and the descriptive cross-sectional research study received the approval of the Radford University Institutional Review Board (IRB). After beta-testing the instrument, attendees at continuing education seminars for architects and professional engineers 


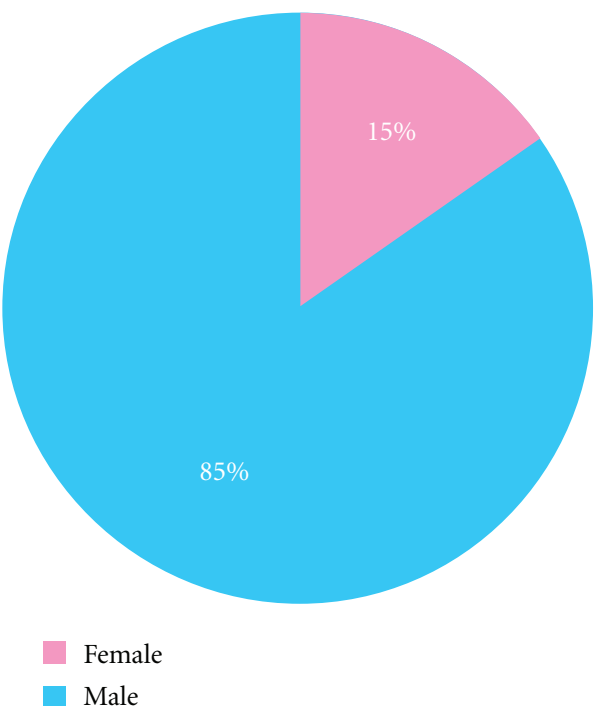

Figure 1: Gender.

were surveyed using a Likert scale and rank-order questionnaire. The questionnaire was designed to be completed immediately after participants registered and before the start of the continuing education seminar. On average, the surveys took approximately 20 minutes to complete. Respondents were asked to answer seven questions first with Likert scale responses followed by an equal number of corresponding rank-order questions for each of three separate subject areas. Finally, respondents were given the opportunity to supply additional written comments and were asked for demographic information regarding gender, age, and occupation title.

During an eight-month period, from March to October 2009, questionnaires were distributed and responses collected at full-day seminars held at eight locations in seven states. These included two "Writing Construction Specification" seminars for architects and professional engineers in Louisville, KY, and Columbia, SC, and six "Technical Writing for Engineers" seminars in Roanoke, VA; Somerset, NJ; Columbia, MD; Fairfax, VA; Salt Lake City, UT; and Clayton, MO.

The principle investigator, Dr. Don Cunningham, collected 185 responses and tabulated the data. Two undergraduate students, Ms. Gabrielle Ness and Ms. Caitlin Webb, under the direct supervision of Dr. Jill Stewart, Chair of the Department of Math and Statistics, used the data for a seniorlevel project in STAT 431 Statistical Consulting class. The two students analyzed the collected data through an array of descriptive statistics. Means, standard deviations, correlation coefficients, and relative frequency distributions were then used to investigate perceptions and relationships.

\section{Responses}

Of the 185 survey participants, 184 responded to the question regarding gender. Male respondents were the majority with 156 males (85\%) compared to 28 females (15\%). Figure 1 illustrates the gender distribution.

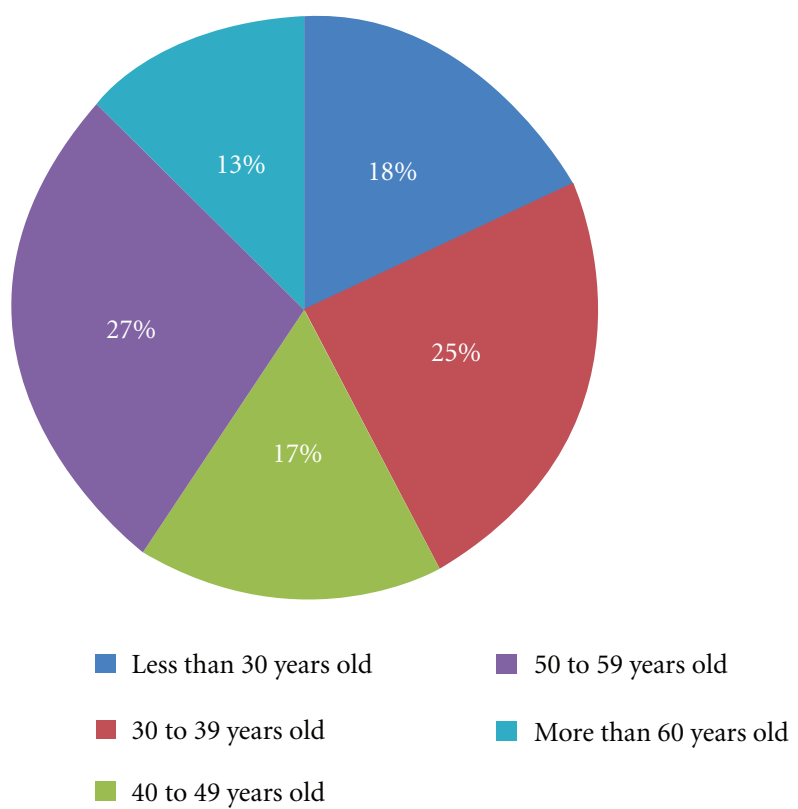

Figure 2: Age.

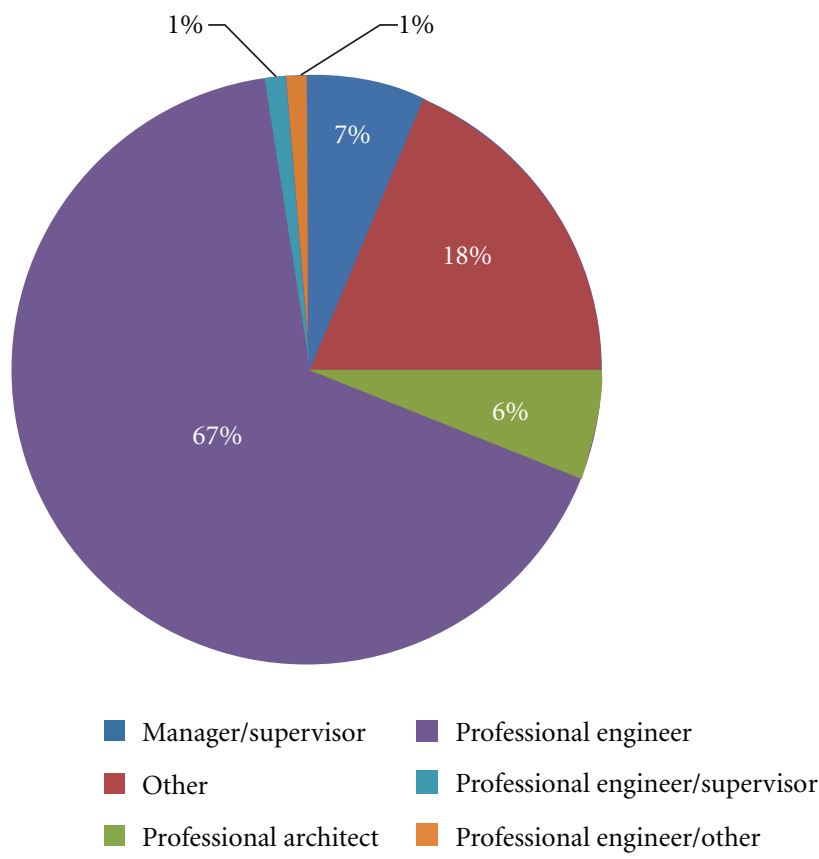

FIgURE 3: Occupation.

Participant ages were fairly equally represented with slightly more in the 50-59 year-old-range. Of the 183 participants answering this question, $33(18 \%)$ were less than 30 years old, 45 (25\%) were $30-39$ years old, 31 (17\%) were 40 49 years old, 51 (27\%) were 50-59 years old, and $23(13 \%)$ were more than 60 years old. Figure 2 illustrates the age group distribution.

For occupation, a few responses indicated multiple choices. Of these, $124(67 \%)$ selected professional engineer including $3(2 \%)$ who indicated both professional engineer 
TABLE 1: Frequency of job-related reading/evaluating written communications questions.

Please respond to the following questions. Select the one response which most accurately reflects your answer. If the situation does not apply to you, select the response labeled "N/A"

\begin{tabular}{|c|c|c|c|c|c|c|}
\hline Doing my job involves... & $\begin{array}{c}\text { Very } \\
\text { Rarely } \\
\end{array}$ & Rarely & Neutral & Often & Very Often & N/A \\
\hline Reading correspondence (letters, e-mail, faxes) & $\square$ & $\square$ & $\square$ & $\square$ & $\square$ & $\square$ \\
\hline Reading meeting minutes & $\square$ & $\square$ & $\square$ & $\square$ & $\square$ & $\square$ \\
\hline Reading technical reports & $\square$ & $\square$ & $\square$ & $\square$ & $\square$ & $\square$ \\
\hline Reading management reports & $\square$ & $\square$ & $\square$ & $\square$ & $\square$ & $\square$ \\
\hline Reading proposals & $\square$ & $\square$ & $\square$ & $\square$ & $\square$ & $\square$ \\
\hline Reading manuals & $\square$ & $\square$ & $\square$ & $\square$ & $\square$ & $\square$ \\
\hline Evaluating documents & $\square$ & $\square$ & $\square$ & $\square$ & $\square$ & $\square$ \\
\hline
\end{tabular}

TABLE 2: Work-related reading or evaluating written communication materials percentage responses.

\begin{tabular}{|c|c|c|c|c|c|c|c|c|}
\hline Question & Very rarely & Rarely & Neutral & Often & Very often & Mean & Std. dev. & Responses \\
\hline Correspondence & 0.6 & 0.0 & 1.7 & 9.9 & 87.8 & 4.86 & 0.48 & 181 \\
\hline Meeting minutes & 5.6 & 14.0 & 16.3 & 36.0 & 28.1 & 3.68 & 1.19 & 178 \\
\hline Technical reports & 1.6 & 3.3 & 13.2 & 42.3 & 39.6 & 4.14 & 0.91 & 182 \\
\hline Management reports & 6.2 & 23.2 & 30.5 & 22.0 & 18.1 & 3.24 & 1.19 & 177 \\
\hline Proposals & 2.8 & 11.0 & 14.9 & 35.9 & 35.4 & 3.90 & 1.10 & 181 \\
\hline Manuals & 0.5 & 6.6 & 18.6 & 35.0 & 39.3 & 4.06 & 0.96 & 183 \\
\hline Evaluating documents & 0.0 & 7.1 & 15.8 & 34.4 & 42.6 & 4.11 & 0.96 & 183 \\
\hline
\end{tabular}

and manager/supervisor or both professional engineer and other. The other respondents included $11(6 \%)$ selecting professional architect, 14 (7\%) selecting manager/supervisor, and $36(18 \%)$ selecting other. Figure 3 illustrates the occupation distribution.

\section{Results and Discussion}

Regarding time spent reading or evaluating technical written communications, respondents were asked to answer questions about frequency of reading six different document types (correspondence, meeting minutes, technical reports, management reports, proposals, and manuals) and frequency of evaluating technical documents. Each question was answered with Likert scale responses ranging from "Very Rarely" to "Very Often." Table 1 shows the Likert scale questions concerning job-related reading/evaluating activities.

Table 2 provides the distribution of percentage responses regarding frequency of work-related reading and evaluating written communication materials. The mean and standard deviation are also presented with participant responses scored from 1 to 5 ("Very Rarely" = 1; "Very Often" = 5).

A repeated measures analysis of variance was used to test the equality of mean responses on the frequency that respondents spend on the seven variables related to reading or evaluating documents. The means were found to be significantly different $(F=3.55, P=.0018)$. Tukey's multiple comparison test reveals that, although the mean perceived frequencies of reading meeting minutes, technical reports, proposals, and manuals are not different, the mean frequencies of reading correspondence and evaluating documents are significantly different from the mean frequency of read=ing management reports. Figure 4 graphically illustrates the means of percentage responses regarding frequency of workrelated reading and evaluating written communication materials. In tabulating the data, participant responses were scored from 1 to 5 ("Very Rarely" = 1; "Very Often" = 5).

Respondents were next asked to indicate their perceptions concerning the relative importance of job-related reading/evaluating activities. In this question, respondents were asked to rank-order reading six different document types (correspondence, meeting minutes, technical reports, management reports, proposals, and manuals) and evaluating technical documents in relation to the importance of their work. Table 3 shows the rank-order question regarding the importance of job-related reading/evaluating activities.

Table 4 provides the distribution of responses regarding importance of work-related reading or evaluating written communication materials. Table 5 indicates the statistical mean and standard deviation of responses regarding importance of work-related reading activities. In tabulating the data, participant responses were scored from 1 to 7 (highest ranking $=1$; lowest ranking $=7$ ).

Figure 5 graphically illustrates the mean rank responses regarding the importance of work-related reading activities. For comparison, participant responses were scored from 1 to 7 (lowest ranking $=1$; highest ranking $=7$ ).

Concerning time spent reading or evaluating technical written communications, architects and professional engineers on average spend the most amount of time reading correspondence such as letters, e-mails, and faxes and the least amount of time reading management reports. Respondents 
TABLE 3: Importance of job-related reading activities question.

Please rank the following activites according to their importance in your work. Place a " 1 " next to the activity that is most important, a " 2 " next to the activity that is next most important, and so on. Remember, no two activities can have the same ranking.

-Reading correspondence (letters, e-mail, faxes)

-Reading meeting minutes

-Reading technical reports

—Reading management reports

- Reading proposals

—Reading manuals

-Evaluating documents

TABLE 4: Importance of work-related reading activities percentage responses.

\begin{tabular}{lcccccccc}
\hline Answer & 1 & 2 & 3 & 4 & 5 & 6 & 7 & Responses \\
\hline Correspondence & 61.3 & 17.7 & 7.2 & 6.1 & 2.8 & 3.3 & 1.7 & 181 \\
Meeting minutes & 0.0 & 13.0 & 11.3 & 18.1 & 24.9 & 13.6 & 19.2 & 177 \\
Technical reports & 17.7 & 23.2 & 23.8 & 19.9 & 7.2 & 7.2 & 1.1 & 181 \\
Management reports & 1.1 & 7.9 & 5.1 & 7.9 & 15.2 & 30.9 & 32.0 & 178 \\
Proposals & 6.7 & 18.5 & 15.2 & 16.3 & 16.9 & 18.0 & 8.4 & 179 \\
Manuals & 4.4 & 9.4 & 19.4 & 13.9 & 15.0 & 17.2 & 20.6 & 180 \\
Evaluating documents & 9.5 & 11.2 & 18.4 & 17.9 & 17.9 & 8.9 & 16.2 & 179 \\
\hline
\end{tabular}

TABLE 5: Importance of work-related reading activities statistical responses.

\begin{tabular}{lccccccc}
\hline Statistic & Correspondence & $\begin{array}{c}\text { Meeting } \\
\text { minutes }\end{array}$ & $\begin{array}{c}\text { Technical } \\
\text { reports }\end{array}$ & $\begin{array}{c}\text { Management } \\
\text { reports }\end{array}$ & Proposals & $\begin{array}{c}\text { Manuals } \\
\text { documents }\end{array}$ \\
\hline Mean & 6.12 & 3.28 & 4.98 & 2.51 & 3.92 & 3.41 & 3.85 \\
Standard deviation & 1.46 & 1.63 & 1.50 & 1.59 & 1.81 & 1.82 & 1.86 \\
\hline
\end{tabular}

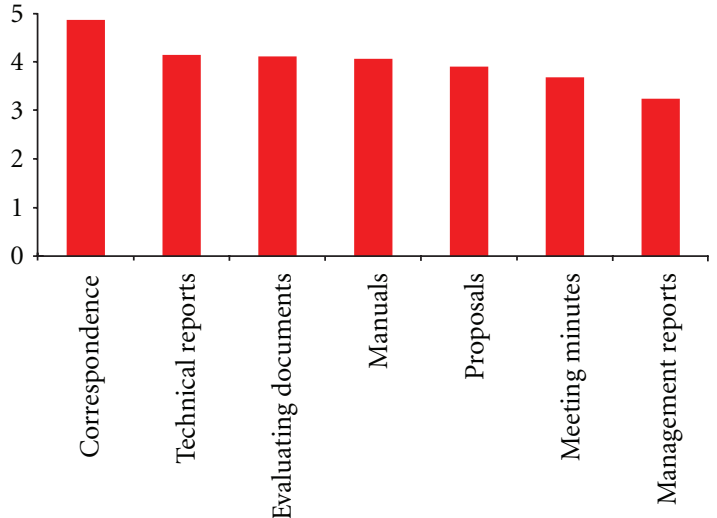

FIGURE 4: Frequency of job-related reading/evaluating written communications questions.

also indicated that they evaluate documents and read technical reports "often" and "very often." Regarding their perceptions of the relative importance of these activities in supporting or meeting their professional objectives, architects and professional engineers considered correspondence to be the most important when compared to other reading activities and ranked evaluating documents below reading technical reports and proposals.

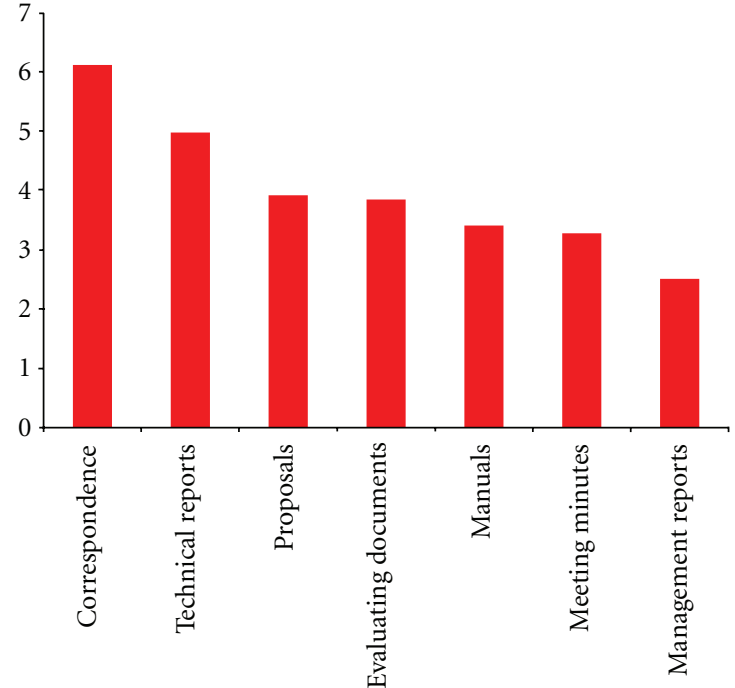

FIGURE 5: Work-related reading activities importance mean rank responses.

Regarding time spent writing or editing technical written communications, respondents were asked to answer questions about frequency of writing six different document types (correspondence, meeting minutes, technical reports, management reports, proposals, and manuals) and frequency of 
TABLE 6: Importance of job-related reading activities questions.

Please respond to the following questions. Select the one response which most accurately reflects your answer. If the situation does not apply to you, select the response labeled "N/A"

\begin{tabular}{|c|c|c|c|c|c|c|}
\hline Doing my job involves... & $\begin{array}{c}\text { Very } \\
\text { Rarely }\end{array}$ & Rarely & Neutral & Often & Very Often & $\mathrm{N} / \mathrm{A}$ \\
\hline Writing correspondence (letters, e-mail, memos, faxes) & $\square$ & $\square$ & $\square$ & $\square$ & $\square$ & $\square$ \\
\hline Writing meeting minutes & $\square$ & $\square$ & $\square$ & $\square$ & $\square$ & $\square$ \\
\hline Writing technical reports & $\square$ & $\square$ & $\square$ & $\square$ & $\square$ & $\square$ \\
\hline Writing management reports & $\square$ & $\square$ & $\square$ & $\square$ & $\square$ & $\square$ \\
\hline Writing proposals & $\square$ & $\square$ & $\square$ & $\square$ & $\square$ & $\square$ \\
\hline Writing manuals & $\square$ & $\square$ & $\square$ & $\square$ & $\square$ & $\square$ \\
\hline Editing other people's writing & $\square$ & $\square$ & $\square$ & $\square$ & $\square$ & $\square$ \\
\hline
\end{tabular}

TABLE 7: Importance of work-related writing/editing activities percentage responses.

\begin{tabular}{lcccccccc}
\hline Question & Very rarely & Rarely & Neutral & Often & Very often & Mean & Std. dev. & Responses \\
\hline Correspondence & 0.0 & 1.1 & 1.6 & 12.6 & 84.7 & 4.83 & 0.49 & 183 \\
Meeting Minutes & 10.5 & 18.6 & 22.7 & 31.4 & 16.9 & 3.29 & 1.24 & 172 \\
Technical Reports & 3.3 & 14.4 & 21.0 & 33.7 & 27.6 & 3.73 & 1.11 & 181 \\
Management Reports & 16.7 & 27.4 & 28.0 & 19.6 & 8.3 & 2.74 & 1.19 & 168 \\
Proposals & 7.5 & 15.6 & 22.5 & 28.9 & 25.4 & 3.49 & 1.24 & 173 \\
Manuals & 24.8 & 29.7 & 23.0 & 14.5 & 7.9 & 2.48 & 1.21 & 165 \\
Editing & 8.9 & 8.9 & 26.3 & 30.7 & 25.1 & 3.58 & 1.22 & 179 \\
\hline
\end{tabular}

TABLE 8: Importance of job-related writing rank order question.

Please rank the following activites according to their importance in your work. Place a " 1 " next to the activity that is most important, a " 2 " next to the activity that is next most important, and so on. Remember, no two activities can have the same ranking.

-Writing correspondence (letters, e-mail, faxes)
-Writing meeting minutes
-Writing technical reports
-Writing management reports
-Writing proposals
-Writing manuals
-Editing other people's writing

editing other people's writing. Each question was answered with Likert scale responses ranging from "Very Rarely" to "Very Often." Table 6 shows the Likert scale questions concerning job-related writing/editing activities.

Table 7 provides the distribution of participant responses regarding frequency of work-related writing or editing written communication materials. The mean and standard deviation are also presented with participant responses scored from 1 to 5 ("Very Rarely" = 1; "Very Often" = 5).

A repeated measures analysis of variance was used to test the equality of mean responses on the frequency that respondents spend on the seven variables related to writing/ editing communications. The means were found to be significantly different $(F=84.55, P<.0001)$. Tukey's multiple comparison test reveals that respondents spend significantly more time writing correspondence than any other document types and significantly less time writing manuals than anything else. Figure 6 graphically illustrates the means for participant responses regarding frequency of work-related writing or editing written communication materials. In tabulating the data, participant responses were scored from 1 to 5 ("Very Rarely" = 1; "Very Often" = 5).

Respondents were next asked to indicate their perceptions concerning the relative importance spent writing and editing technical written communications. In this question, respondents were asked to rank-order writing six different document types (correspondence, meeting minutes, technical reports, management reports, proposals, and manuals) and editing other people's writing in relation to the importance of their work. Table 8 shows the rank- order question regarding the importance of job-related writing/editing activities.

Table 9 provides the distribution of responses regarding importance of work-related writing or editing written communication materials. Table 10 indicates the statistical mean and standard deviation of responses regarding importance 
TABLE 9: Importance of work-related writing/editing activities percentage responses.

\begin{tabular}{lcccccccc}
\hline Answer & 1 & 2 & 3 & 4 & 5 & 6 & 7 & Responses \\
\hline Correspondence & 67.4 & 16.0 & 9.9 & 3.9 & 1.1 & 1.1 & 0.6 & 181 \\
Meeting minutes & 0.0 & 19.0 & 16.2 & 20.7 & 19.6 & 10.6 & 14.0 & 179 \\
Technical reports & 22.2 & 25.0 & 19.4 & 11.1 & 11.1 & 10.0 & 1.1 & 180 \\
Management reports & 1.1 & 7.3 & 6.8 & 11.3 & 22.0 & 27.7 & 23.7 & 177 \\
Proposals & 7.8 & 19.4 & 18.3 & 18.3 & 15.6 & 15.0 & 5.6 & 180 \\
Manuals & 0.0 & 3.4 & 7.3 & 12.4 & 14.6 & 23.6 & 38.8 & 178 \\
Editing & 2.2 & 11.1 & 22.8 & 22.2 & 15.6 & 10.6 & 15.6 & 180 \\
\hline
\end{tabular}

TABLE 10: Importance of work-related writing/editing activities statistical responses.

\begin{tabular}{lcccccrc}
\hline Statistic & Correspondence & $\begin{array}{c}\text { Meeting } \\
\text { minutes }\end{array}$ & $\begin{array}{c}\text { Technical } \\
\text { reports }\end{array}$ & $\begin{array}{c}\text { Management } \\
\text { reports }\end{array}$ & Proposals & Manuals & Editing \\
\hline Mean & 6.39 & 3.72 & 5.02 & 2.76 & 4.18 & 2.36 & 3.68 \\
Standard deviation & 1.09 & 1.65 & 1.67 & 1.55 & 1.70 & 1.45 \\
\hline
\end{tabular}

TABLE 11: Technical documents quality characterstics questions.

Please respond to the following questions. Select the one response which most accurately reflects your answer.

\begin{tabular}{|c|c|c|c|c|c|}
\hline Technical documents should... & Very Trivial & Trivial & Neutral & Crucial & Very Crucial \\
\hline Cover topic with appropriate and proper detail & $\square$ & $\square$ & $\square$ & $\square$ & $\square$ \\
\hline Use precise language to express meaning & $\square$ & $\square$ & $\square$ & $\square$ & $\square$ \\
\hline Provide a true understanding and representation of the subject & $\square$ & $\square$ & $\square$ & $\square$ & $\square$ \\
\hline Use simple, direct language & $\square$ & $\square$ & $\square$ & $\square$ & $\square$ \\
\hline Be grammatically correct & $\square$ & $\square$ & $\square$ & $\square$ & $\square$ \\
\hline Describe information Importance and implications & $\square$ & $\square$ & $\square$ & $\square$ & $\square$ \\
\hline Not have misspelled words & $\square$ & $\square$ & $\square$ & $\square$ & $\square$ \\
\hline
\end{tabular}

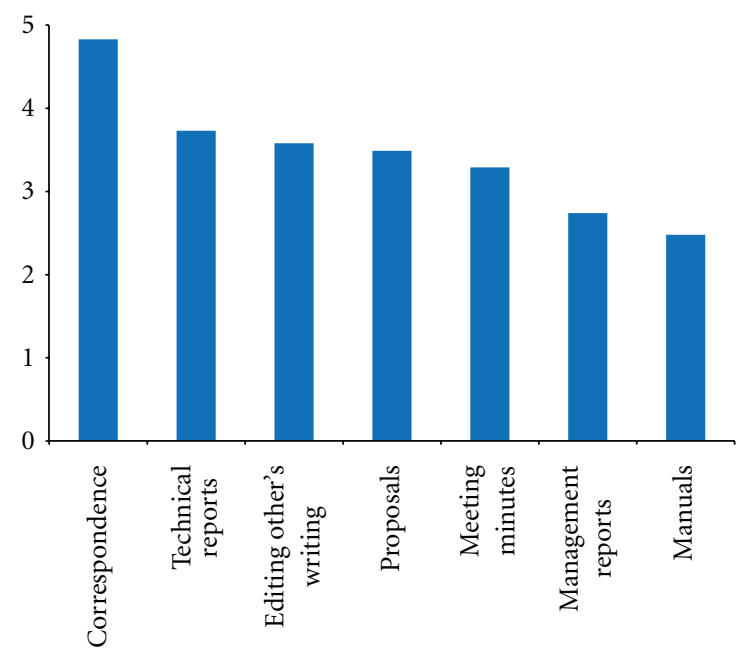

FIGURE 6: Writing/editing questions mean Likert responses.

of work-related writing/editing activities. In tabulating the data, participant responses were scored from 1 to 7 (highest ranking $=1$; lowest ranking $=7$ ).

Figure 7 graphically illustrates the mean rank responses regarding the importance of work-related writing/editing activities. For comparison, participant responses were scored from 1 to 7 (lowest ranking $=1$; highest ranking $=7$ ).

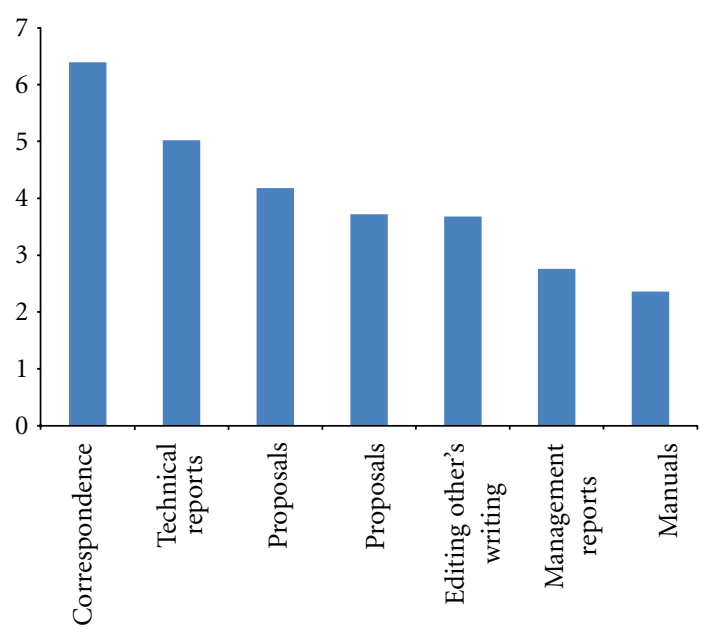

FIGURE 7: Importance of work-related writing/editing activities mean rank responses.

Concerning time spent writing and editing technical written communications, architects and professional engineers spend the most amount of time writing correspondence such as letters, e-mails, and faxes, closely followed by nearly equal time spent writing technical reports and proposals and editing other people's writing. Regarding their perceptions of the relative importance of these activities in 
TABLE 12: Quality characteristics of technical documents percentage responses.

\begin{tabular}{|c|c|c|c|c|c|c|c|c|}
\hline Question & Very trivial & Trivial & Neutral & Crucial & Very crucial & Mean & $\begin{array}{l}\text { Std. } \\
\text { dev. }\end{array}$ & Responses \\
\hline Cover topic with appropriate and proper detail & 0.0 & 0.6 & 5.0 & 44.2 & 50.3 & 4.45 & 0.61 & 181 \\
\hline Use precise language to express meaning & 0.0 & 0.5 & 13.2 & 45.1 & 41.2 & 4.27 & 0.70 & 182 \\
\hline $\begin{array}{l}\text { Provide a true understanding and representation } \\
\text { of the subject }\end{array}$ & 0.0 & 0.0 & 2.2 & 43.7 & 54.1 & 4.52 & 0.54 & 183 \\
\hline Use simple, direct language & 0.0 & 0.6 & 14.4 & 49.2 & 35.9 & 4.21 & 0.70 & 181 \\
\hline Be grammatically correct & 0.0 & 2.2 & 16.3 & 47.8 & 33.7 & 4.13 & 0.76 & 184 \\
\hline $\begin{array}{l}\text { Describe information importance and } \\
\text { implications }\end{array}$ & 0.0 & 1.1 & 11.0 & 49.5 & 38.5 & 4.23 & 0.73 & 182 \\
\hline Not have misspelled words & 0.0 & 3.8 & 19.8 & 41.2 & 35.2 & 4.06 & 0.86 & 182 \\
\hline
\end{tabular}

TABLE 13: Importance of Job-Related Writing Rank Order Question.

Please rank the following characterstics according to their importance in technical documentation. Place a " 1 " next to the characterstics that is most important, a "2" next to the characterstics that is next most important, and so on. Remember, no two characterstics can have the same ranking.

-Cover topic with appropriate and proper detail

-Use precise language to express meaning

-Provide a true understanding and representation of the subject

-Uses simple, direct language

-Is grammatically correct

—Describes information importance and implications

—Words are spelled correctely

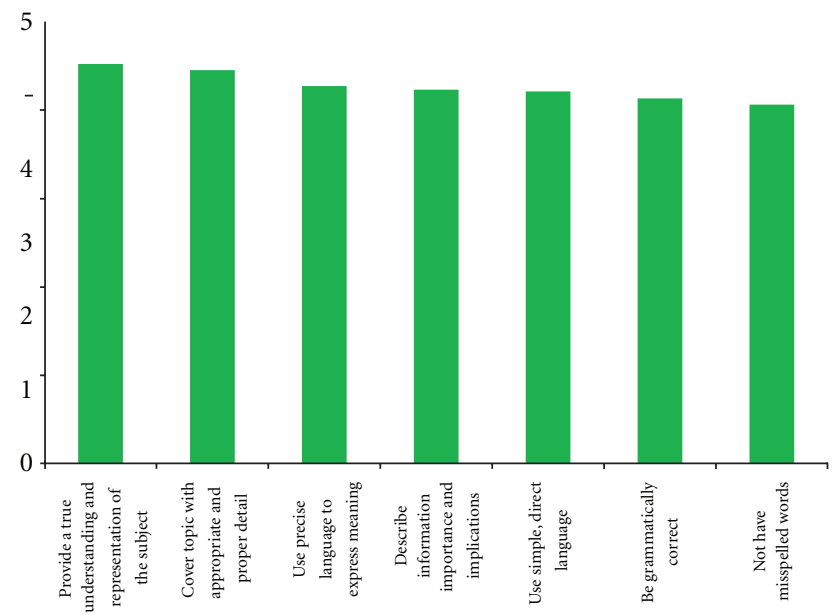

FIGURE 8: Quality characteristics for technical documents mean Likert responses.

supporting or meeting their professional objectives, architects and professional engineers considered correspondence to be the most important when compared to other writing activities in their work. Writing technical reports and proposals were ranked second and third, respectively, with manuals rating the lowest level of importance.

Regarding specific quality characteristics of technical written communications, respondents were asked to answer questions about the need for seven aspects (completeness,

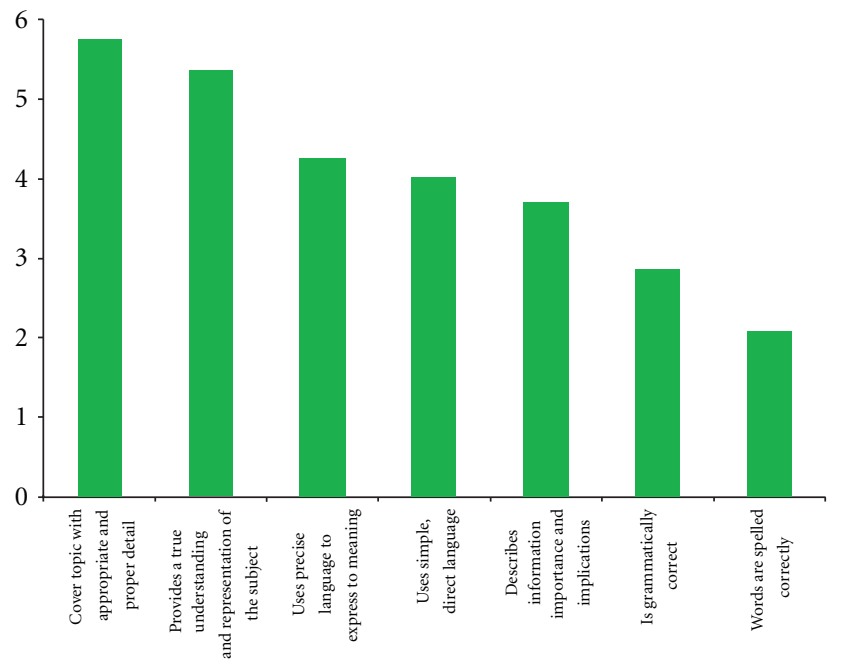

FIGURE 9: Importance of quality characteristics mean rank responses.

stylistic accuracy, technical accuracy, appropriateness, conciseness, correct grammar, and spelling) in technical documents. Each question was answered with Likert scale responses ranging from "Very Trivial" to "Very Crucial." Table 11 shows the Likert scale questions concerning specific quality characteristics for technical communications.

Table 12 provides the distribution of responses regarding quality characteristics of technical documents. The mean 
TABLE 14: Importance of quality characteristics percentage responses.

\begin{tabular}{lcccccccc}
\hline Answer & 1 & 2 & 3 & 4 & 5 & 6 & 7 & Responses \\
\hline Covers topic with appropriate and proper detail & 50.5 & 15.9 & 13.2 & 8.2 & 4.9 & 5.5 & 1.6 & 182 \\
Uses precise language to express meaning & 6.1 & 18.2 & 15.5 & 30.9 & 18.8 & 6.1 & 4.4 & 181 \\
Provides a true understanding and representation of & 23.9 & 32.2 & 21.1 & 9.4 & 7.2 & 4.4 & 1.7 & 180 \\
the subject & & & & & & & & \\
Uses simple, direct language & 3.8 & 10.5 & 17.7 & 22.1 & 24.3 & 11.6 & 5.0 & 181 \\
Is grammatically correct & 3.3 & 7.1 & 4.4 & 8.8 & 20.3 & 45.6 & 10.4 & 182 \\
Describes information importance and implications & 2.2 & 12.7 & 22.7 & 16.6 & 19.9 & 13.8 & 12.2 & 181 \\
Words are spelled correctly & 5.5 & 4.4 & 5.5 & 3.9 & 3.9 & 12.7 & 64.1 & 181 \\
\hline
\end{tabular}

TABLE 15: Importance of quality characteristics statistical responses.

\begin{tabular}{|c|c|c|c|c|c|c|c|}
\hline Statistic & $\begin{array}{c}\text { Covers topic with } \\
\text { appropriate and } \\
\text { proper detail }\end{array}$ & $\begin{array}{c}\text { Uses precise } \\
\text { language to } \\
\text { express } \\
\text { meaning }\end{array}$ & $\begin{array}{c}\text { Provides a true } \\
\text { understanding and } \\
\text { representation of } \\
\text { the subject }\end{array}$ & $\begin{array}{c}\text { Uses simple, } \\
\text { direct } \\
\text { language }\end{array}$ & $\begin{array}{c}\text { Is grammati- } \\
\text { cally } \\
\text { correct }\end{array}$ & $\begin{array}{c}\text { Describes } \\
\text { information } \\
\text { importance and } \\
\text { implications }\end{array}$ & $\begin{array}{c}\text { Words are } \\
\text { spelled } \\
\text { correctly }\end{array}$ \\
\hline Mean & 5.76 & 4.26 & 5.26 & 4.03 & 2.86 & 3.71 & 2.09 \\
\hline Standard deviation & 1.63 & 1.48 & 1.49 & 1.60 & 1.52 & 1.65 & 1.85 \\
\hline
\end{tabular}

and standard deviation is also presented with participant responses scored from 1 to 5 ("Very Rarely" = 1; "Very Often" = 5).

A repeated measures analysis of variance was used to test the equality of mean importance for the different quality characteristics of technical documents. The means were found to be significantly different $(F=14.33, P<.0001)$. Tukey's multiple comparison test reveals that respondents think "providing a true understanding and representation of the subject" is significantly more important than all other quality characteristics of technical documents except "covering a topic with appropriate and proper detail." Figure 8 graphically illustrates the means for participant responses regarding quality characteristics of technical documents. In tabulating the data, participant responses were scored from 1 to 5 ("Very Rarely" = 1; "Very Often" $=5$ ).

Respondents were next asked to indicate their perceptions concerning the relative value of the quality characteristics for effective technical communication. In this question, respondents were asked to rank-order the importance of seven quality aspects (completeness, stylistic accuracy, technical accuracy, appropriateness, conciseness, correct grammar, and spelling) in relation to the effectiveness of technical documents. Table 13 shows the rank-order question regarding the importance of specific quality characteristics for effective technical communication.

Table 14 provides the distribution of responses regarding importance of regarding the importance of the seven quality characteristics for effective technical communication. Table 15 indicates the statistical mean and standard deviation of responses regarding the importance of the seven quality characteristics for effective technical communication. In tabulating the data, participant responses were scored from 1 to 7 (highest ranking $=1$; lowest ranking $=7$ ).

Figure 9 illustrates the mean rank responses (least impor$\operatorname{tant}=1$; most important $=7$ ) regarding the importance of the seven quality characteristics for effective technical communication. For comparison, participant responses were scored from 1 to 7 (lowest ranking $=1$; highest ranking $=$ 7).

Regarding specific quality characteristics (completeness, stylistic accuracy, technical accuracy, appropriateness, conciseness, grammar, and misspellings) considered in evaluating technical documents architects and professional engineers thought it is "very crucial" for a technical document to provide a true understanding and representation of the subject and to cover the topic with appropriate and proper detail. Concerning their perceptions of the relative value of the quality characteristics for effective technical communication, respondents valued mechanical issues such as spelling and grammatical correctness as the two least important aspects of a technical document. On the other hand, respondents rated organization, comprehensiveness, and accuracy as the most important aspects of a technical document.

\section{Conclusion}

One purpose of postsecondary education is to prepare students to effectively plan and write a range of informative and persuasive documents essential to their professional careers. Engineering and technical communication curricula emphasis should help students understand and develop specific professional writing skills. Students expect that what the instructor focuses on in the classroom will also apply to their workplace writing. This requires close parity between what professors teach and what practitioners find important. This study has revealed interesting results regarding the perceptions of time spent by architects and professional engineers on reading, writing, and evaluating various information products, as well as their perspectives of specific quality characteristics and the relative significance in meeting work goals. 
What we learned from this descriptive cross-sectional research study suggests the primary pedagogical emphasis for engineering and technical communication curricula should be job-related correspondence, followed closely by technical reports and proposals. By comparison, less attention could be directed at the genre of writing instructional materials such as manuals. Finally, developing rhetorical strategies for focusing attention on audience and purpose to plan well-organized and comprehensive written communications should be considered more important than concentrating on style, grammar, and other mechanical writing/editing competencies.

An ethnographic study is needed to assess post-secondary educators' perceptions of writing quality and how it may be affected by pedagogical influence. However, the results of this study may assist educators to relate more closely with industry expectations and decide whether curricula emphasis should be revised based on feedback from professional practitioners. Educators may find such definitive information useful in defining objectives, planning curricula, and determining specific course criteria for developing engineering and technical writing programs.

A secondary aspect of this research is to clarify perceptions regarding the importance of specific quality characteristics for information products. Communication practitioners may also consider the value of various aspects as perceived by their colleagues helpful when making strategic decisions to create or enhance information products.

\section{References}

[1] P. Anderson, Technical Communication, Wadsworth Publishing. , Florence, Ky, USA, 7th edition, 2010.

[2] P. Sageev and C. J. Romanowski, "A message from recent engineering graduates in the workplace: results of a survey on technical communication skills," Journal of Engineering Education, vol. 90, no. 4, pp. 685-742, 2001.

[3] National Commission on Writing. (NCW), Writing: A Ticket to Work...or a Ticket Out, New York, NY, USA, 2004, http://www.collegeboard.com/prod_downloads/writingcom/ writing-ticket-to-work.pdf.

[4] STC Certification, 2011, http://www.stc.org/education/certification/certification-main.

[5] C. R. Lanier, "Analysis of the skills called for by technical communication employers in recruitment postings," Technical Communication, vol. 56, no. 1, pp. 51-61, 2009.

[6] Commission on Writing (NCW) National, The Neglected " $R$ ": The Need for a Writing Revolution, New York, NY, 2003, http://www.collegeboard.com/prod_downloads/writingcom/ neglectedr.pdf.

[7] C. Paine, P. Anderson, and B. Gonyea, "NSSE experimental questions on writing: selected results," in Proceedings of the Writing Program Administration and/as Learning (WPA '08), Denver, Colo, USA, 2008.

[8] N. Allen and S. Benninghoff, "TPC program snapshots: developing curricula and addressing challenges," Technical Communication Quarterly, vol. 13, no. 2, pp. 157-185, 2004.

[9] E. Kaneko, W. Rozycki, and T. Orr, "Survey of workplace English needs among computer science graduates," in Proceedings of the IEEE International Professional Communication Conference (IPCC '09), Commitment to Excellence, Honolulu, Hawaii, USA, 2009.

[10] D. Cunningham, "Trends in curricular matters for science and technology journalism," in Proceedings of the IEEE Conference on the Convergence of Technology and Professional Communication: Racing into the Future, Saratoga Springs, NY, USA, 2006.

[11] W. Hart-Davidson, "On writing, technical communication, and information technology: the core competencies of technical communication," Technical Communication, vol. 48, no. 2, pp. 145-155, 2001.

[12] K. T. Rainey, R. K. Turner, and D. Dayton, "Do curricula correspond to managerial expectations? Core competencies for technical communicators," Technical Communication, vol. 52, no. 3, pp. 323-352, 2005.

[13] R. Turner and K. Rainey, "Certification in technical communication," Technical Communication Quarterly, vol. 13, no. 2, pp. 211-234, 2005.

[14] A. Whiteside, Bridging theory and practice: an investigation of recent technical communication graduates in business and industry, M.S. thesis, University of Minnesota, Minneapolis, Minn, USA, 2002.

[15] A. L. Whiteside, "The skills that technical communicators need: an investigation of technical communication graduates, managers, and curricula," Journal of Technical Writing and Communication, vol. 33, no. 4, pp. 303-318, 2003.

[16] S. Smith, "What is "good" technical communication? A comparison of the standards of writing and engineering instructors," Technical Communication Quarterly, vol. 12, no. 1, pp. 7-24, 2003.

[17] N. Amare and C. Brammer, "Perceptions of memo quality: a case study of engineering practitioners, professors, and students," Journal of Technical Writing and Communication, vol. 35, no. 2, pp. 179-190, 2005. 